\title{
CONFIGURANDO OS CONTEXTOS DE OCORRÊNCIADOS PRETÉRITOS PERFEITO E MAIS-QUE-PERFEITO
}

\author{
Márluce Coan
}

RESUMO: This paper aims at dealing with anteriority to a past reference point, codified in Portuguese as "pretérito mais-que-perfeito composto" (pluperfect) or "pretérito perfeito" (simple past) verb forms, analysing data from "Projeto VARSUL" (Variação Lingüística Urbana na Região Sul). The results have characterized the phenomenon as a complex functional domain, influenced by motivations of a different nature: linguistic and social.

PALAVRAS-CHAVE: pretérito mais-que-perfeito, pretérito perfeito, motivações

\section{PRELIMINARES}

Neste trabalho, tratamos da relação temporal de anterioridade estabelecida relativamente a um ponto de referência passado, postulando que esta função é codificada em português por formas alternantes - pretérito mais-que-perfeito versus pretérito perfeito, configurando-se um fenômeno de variação lingüística.

Partindo de uma função comunicativa/discursiva, inserimo-nos no quadro teórico do Funcionalismo Lingüístico; investigando as formas variantes que codificam tal função, colocamo-nos na perspectiva da Teoria da Variação. A variável em questão é situada no nível morfossintático-discursivo, e fatores de naturezas diversas são controlados como possíveis condicionantes da escolha de uma ou de outra forma verbal.

A amostra desta pesquisa integra o Banco de Dados do Projeto VARSUL (Variação Lingüística Urbana na Região Sul), sendo constituída de dados de trinta e seis informantes nativos de Florianópolis, estratificados de acordo com a idade, o sexo e a escolaridade.

Márluce Coan é professora da UNESC - Criciúma -SC 


\section{O FENÔMENO EM ESTUDO}

Considerem-se os seguintes exemplos:

(1) ... ela falou que FIZERAM a reação com o sangue e DEU positivo. (FLP 20, L1206)

(2) ... ela foi lá falar com a Telma que TINHA DADO positivo, que TINHA FICADO bem azulzinho. (FLP 20, L1204)

Dificilmente um falante do português diria que (2) é gramaticalmente melhor do que (1) por trazer a forma verbal de pretérito mais-que-perfeito indicando um tempo passado anterior a outro passado; ou que (1) é gramaticalmente mal construído por apresentar verbos no pretérito perfeito expressando anterioridade a um tempo passado.

Um passeio por nossas gramáticas normativas revela que por esse caminho é quase impossível discernir usos e valores desses dois tempos verbais. Said Ali (1964) e Rocha Lima (1976) limitam-se a dizer que existem três modalidades de pretérito que expressam fatos anteriores ao momento em que se fala: perfeito, imperfeito e mais-que-perfeito, sem especificar seus usos. Almeida (1982) e Cunha \& Cintra (1985) afirmam que o pretérito mais-que-perfeito indica uma ação que ocorreu antes de outra ação passada. Embora os autores associem a forma verbal a uma função particular, a definição permanece vaga e traz problemas: o pretérito mais-que-perfeito indica somente ação? Indicar "uma ação que ocorreu antes de outra ação passada" é suficiente para determinar os contextos de uso dessa forma verbal?

$\mathrm{Na}$ verdade, quando se diz que uma forma verbal indica uma ação que ocorreu antes de outra ação passada, abre-se um leque de possibilidades para seu uso. Considerem-se algumas ocorrências:

(3) Eu antes ESTUDEI até o ginásio. Depois de dez anos, aí eu FIZ o segundo grau. (FLP 17, L08)

(4) Então CHEGÁVAMOS em casa, APANHÁVAMOS uma surra do pai... (FLP 18, L1123)

Nos dois casos de seqüencialidade acima exemplificados, as situações expressas por 'estudei até o ginásio' e 'chegávamos em casa' ocorreram respectivamente antes das situações passadas 'fiz o segundo grau' e 'apanhávamos uma surra'. Deveriam ou poderiam ser indicadas pelo pretérito mais-que-perfeito?

Similarmente, há casos de codificação contra-seqüencial que mostram situações anteriores a outras passadas:

Para maiores detalhes, verificar Coan, (1997, p.42).

56 
Em (5), trabalhava é anterior a acabou saindo, logo o tempo verbal para sua codificação seria o pretérito mais-que-perfeito?

Inúmeros outros exemplos com diferentes formas verbais poderiam ser elencados e discutidos à luz das definições propostas pelos gramáticos para pretérito mais-que-perfeito, reafirmando a inadequação das referidas definições.

Câmara Jr. (1985), entretanto, enfatiza a existência de um outro componente na caracterização do pretérito mais-que-perfeito, ao estabelecer uma oposição entre aspecto inconcluso (imperfeito) e concluso (perfeito) num primeiro pretérito, situando dentro do aspecto concluso um segundo pretérito (mais-queperfeito) mais remoto, já concluso por ocasião de outro pretérito. Assim, não basta que uma ação seja passada em relação a outra passada, é preciso que o aspecto concluso esteja evidenciado.

Tal restrição aspectual parece excluir os casos (4) e (5), que trazem formas imperfectivas, mas parece não atingir (3), onde 'estudei até o ginásio' é mais remoto e já concluso por ocasião de 'fiz o segundo grau', portanto, passível de ser interpretado como mais-que-perfeito.

A obscuridade conceitual acima apontada obviamente se reflete no uso das formas verbais, que teriam seu uso variável, por princípio, plenamente justificado. Mas muitas questões ainda permanecem.

Que elementos deveriam, então, ser considerados na definição do pretérito mais-que-perfeito para torná-la adequada? Cremos que se deva levar em conta noções de tempo, aspecto e ponto de referência.

$\mathrm{O}$ interesse desta pesquisa volta-se para o valor temporal do pretérito mais-que-perfeito, ou seja, para sua utilização referindo uma situação transcorrida antes de uma outra em tempo passado. Dizemos isso porque o pretérito mais-queperfeito pode adquirir diferentes valores: pode denotar um fato vago no passado ou uma atenuação, evidenciando o seu valor modal; pode substituir o futuro do pretérito e o imperfeito do subjuntivo preenchendo as funções lingüísticas que tais formas codificam, adquirindo outro valor temporal; e em casos de frases exclamativas, expressa uma projeção futura ${ }^{1}$.

Não trataremos, neste trabalho, do pretérito mais-que-perfeito simples. Essa forma foi encontrada apenas em enunciados exclamativos que mencionam uma expectativa futura, portanto, destituída de seu valor temporal básico (cf. ex. $6)$.

(6) TOMARA que eu esteja enganado! (FLP 21, L666)

Em relação ao pretérito perfeito, temos observado que este pode ser utilizado também para codificar um tempo passado anterior a outro passado. Diferenciamos, então, o pretérito perfeito simples, o que codifica, via de regra, um 
tempo passado vinculado ao tempo de fala, do passado anterior, o que aparece em lugar do pretérito mais-que-perfeito. ${ }^{2}$

O aspecto, mencionado por Mattoso Câmara (1985), também é importante na conceituação do pretérito mais-que-perfeito. Utilizamos a definição de aspecto dada por Comrie (1981, p..3): "Aspectos são diferentes modos de ver a constituição temporal interna de uma situação". E classificamos os pretéritos sob análise como perfectivos já que a situação é vista como um todo único, sem distinção das fases que a constituem.

$\mathrm{Na}$ literatura lingüística sobre aspecto, encontra-se freqüentemente uma correlação entre aspecto perfectivo e situação de curta duração, por um lado, e entre aspecto imperfectivo e situação de longa duração, por outro. Para Comrie (1981), porém, é possível utilizar os dois tipos aspectuais para fazer referência a uma extensão temporal, o que vale dizer que uma situação perfectiva pode ser vista em fases, ou seja, pode apresentar estrutura interna desde que isso não afete a visão da situação como um todo único (Então ela acabou saindo do serviço, ela trabalhava lá, que ela perdeu muito serviço. ( FLP03, L1187).

A noção de ponto de referência também é crucial na interpretação das formas de pretérito perfeito e pretérito mais-que-perfeito como anteriores no tempo. Ponto de referência é um segmento passado na linha temporal ao qual as variantes estão vinculadas, por tal razão, são passíveis de serem interpretadas como anteriores.

Relacionados ao ponto de referência, os tempos podem ser classificados como absolutos, relativos e relativo-absolutos. O tempo verbal absoluto, conforme Comrie (1990), tem o momento presente como ponto de referência, o que já é parte de seu significado. Já o tempo relativo tem um ponto de referência dado pelo contexto lingǘstico. Comrie (1990, p.58) diz que "tudo que é requerido para tempos verbais relativos é a identificação de um ponto de referência compatível com o contexto dado. Tempos relativos podem ser representados por formas verbais não finitas e finitas. Uma forma não finita indicará um tempo relativo puro; já a forma finita indicará um tempo relativo-absoluto (o pretérito mais-queperfeito, por exemplo).

\section{QUADRO TEÓRICO}

Nesta seção, apresentam-se os pressupostos básicos da Sociolingüística laboviana, com ênfase na questão da variável (sócio) lingüística, evidenciando aspectos que possibilitam o enquadramento do fenômeno em estudo dentro da Teoria da Variação. Apresentam-se também pressupostos e princípios básicos do

\footnotetext{
${ }^{2}$ Formas na terceira pessoa do plural, que poderiam ser classificadas indistintamente como pretérito mais-que-perfeito simples ou pretérito perfeito, já que homônimas, foram classificadas como pretérito perfeito. Como não encontramos dados de pretérito mais-que-perfeito simples referentes às demais pessoas do discurso, mas muitos dados de perfeito, supomos que tais formas sejam de pretérito perfeito. 58
} 
Funcionalismo Lingüístico, especialmente de base givoniana, que, associados aos postulados variacionistas, constituem o quadro teórico em que se insere esta pesquisa.

\section{Teoria da variação}

A Teoria da Variação e Mudança Lingüística (também chamada Sociolingüística Quantitativa) tem como objeto de estudo a estrutura e evolução da língua dentro do contexto social da comunidade de fala. A língua passa, então, a ser vista como um sistema heterogêneo. Esse alargamento da concepção de sistema para abrigar a variação e a mudança lingüística traz consigo a noção de regra variável. Regras variáveis são concebidas como inerentes ao sistema, como padrões sistemáticos previsíveis que emergem a partir da língua em uso.

Assumindo a perspectiva de que é impossível entender o desenvolvimento de uma mudança lingüística fora da vida social da comunidade, já que pressões sociais estão continuamente operando sobre a linguagem, Labov se propõe, em seus trabalhos pioneiros ${ }^{3}$, a correlacionar os padrões lingüísticos variáveis a diferenças paralelas na estrutura social em que os falantes estão inseridos. De fato, investigando variáveis fonológicas, o autor constata uma forte correlação entre a estratificação social dos falantes e seus usos lingüísticos diferenciados.

As pesquisas labovianas podem ser caracterizadas em duas grandes fases: a primeira, em que o autor considera que diferenças na forma (que não alteram o sentido) trazem consigo significado social ou estilístico; a segunda, em que admite que o uso de formas diferentes é condicionado por fatores lingüísticos estruturais (mecânicos), e as formas não apresentam significado social ou estilístico. Essas fases mostram a ampliação dos níveis de análise, da fonologia para a sintaxe/discurso, na medida em que tratam de variáveis fonológicas e sintáticas e de condicionamentos fonológicos, morfológicos, sintáticos e discursivos (status informacional, por exemplo). Esse alargamento se constitui, no entanto, em ponto de controvérsia.

Lavandera (1978) diz que unidades para além do nível fonológico têm cada uma um significado, e questiona: se cada construção sintática tem um significado, como podemos ter variação se por variação entendemos duas maneiras de dizer a mesma coisa? A autora propõe alargar a condição de mesmo significado para "comparabilidade funcional" (p.181).

Labov (1978) responde à questão proposta por Lavandera lançando mão da noção de "significado representacional" (ou referencial). O autor utiliza a expressão "estado de coisas" para indicar esse significado representacional e postula que "dois enunciados que se referem ao mesmo estado de coisas têm o mesmo significado representacional ou o mesmo valor de verdade" (p.2).

\footnotetext{
${ }^{3}$ The social motivation of a sound change (1963) e The social stratification of (r) in New York city department stores (1966), ambos publicados em Sociolinguistic Patterns (1972b).
} 
A extensão do modelo variacionista para tratar fenômenos sintáticodiscursivos "abriu as portas à incorporação de hipóteses funcionalistas, no sentido de atribuir a motivações fora da estrutura da língua, decorrentes de necessidades comunicativo-funcionais, a origem da variação" (PAREDES, 1993, p.885). É neste contexto teórico-metodológico que se inscreve a presente pesquisa.

\section{Funcionalismo lingüístico}

Analisando a língua em seu funcionamento numa comunidade de fala específica, estamos privilegiando a função comunicativa da linguagem. E, para entender o fenômeno lingüístico enquanto comunicação, é necessário que se estabeleçam correlações entre os mecanismos gramaticais e os contextos discursivos em que se manifestam; em outras palavras, é preciso verificar a gramática-no-texto (GIVÓN, 1990, 1993, 1995).

Segundo Givón, a gramática deve ser interpretada como "instruções de processamento mental" (1991, p.7), portanto, como parte do "complexo mapeamento entre pensamento e fala" (1995, p.305). Ou ainda como "um conjunto de estratégias empregadas para se produzir uma comunicação coerente" (1993, p.1). Nesse caso, tanto a função comunicativa quanto a coerência podem ser definidas em duas direções: metodológica/heuristicamente, como um artefato observável no texto; ou cognitivamente, como um processo na mente de quem produz e compreende textos (1995, p.343).

Em seu nível mais concreto, a gramática pode ser vista como um instrumento de codificação lingüística. O nível da codificação relaciona-se aos domínios cognitivo-funcionais básicos da comunicação humana, conforme esquematizado (op.cit., p.405):

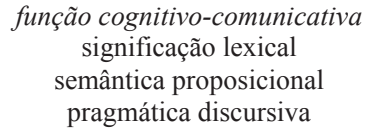

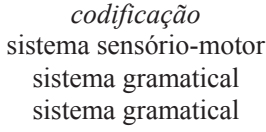

Num primeiro nível, palavras codificam conceitos através de sons. Num segundo nível, a gramática codifica articuladamente dois domínios funcionais: a informação proposicional em oração e a coerência textual das orações em seu contexto discursivo. Assim, a gramática abarca não só construções sentenciais, mas também o discurso multi-proposicional. Nesse alargamento do escopo gramatical, se prevê a existência de motivações em competição, na medida em que alguns elementos gramaticais podem atender mais a exigências do domínio funcional relativo à informação proposicional, enquanto outros podem servir mais à função discursiva.

Os princípios gerais que orientam a teoria funcionalista givoniana são os da iconicidade e da marcação (GIVÓN, 1991b). Citamos, a seguir, apenas o princípio da marcação, já que será mais diretamente verificado. 
"Categorias que são cognitivamente marcadas (i.é., complexas) tendem a ser marcadas estruturalmente." (p.106)

O autor apresenta três critérios para se avaliar a marcação:

(a) Complexidade estrutural - "a estrutura marcada tende a ser mais complexa (ou maior) do que a não-marcada."

(b) Distribuição de freqüência - "a categoria marcada tende a ser menos freqüente do que a não marcada."

(c) Complexidade cognitiva - "a categoria marcada tende a ser cognitivamente mais complexa, em termos de demandar maior atenção, mais esforço mental e tempo de processamento do que a não marcada.” (p. 106)

Esses vários aspectos da marcação devem ser examinados independentemente e depois correlacionados, a partir de resultados empíricos, para se evitar circularidade (GIVÓN, 1995, p.59). Segundo Givón, uma correlação função-forma somente é válida se for testada em dados reais, e mostrada através de quantificação estatística (op.cit., p. 20).

\section{PROCEDIMENTOS TEÓRICOS METODOLÓGICOS}

\section{As restrições}

Para demonstrar que as formas verbais de pretérito mais-que-perfeito e pretérito perfeito compõem um "envelope de variação", traçamos quatro restrições que nos permitiram, por um lado, delimitar criteriosamente as variantes em estudo, caracterizando seu contexto de uso, e, por outro, descartar possíveis formas concorrentes à variação.

A restrição relacional impede que passem à próxima etapa situações que não mantêm uma relação de anterioridade com um ponto de referência passado, conforme o diagrama abaixo:

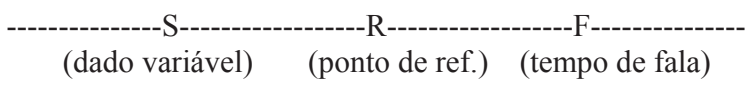

A restrição aspectual atua filtrando apenas situações de aspecto perfectivo, ou seja, aquelas vistas como um todo único (COMRIE, 1990).

A restrição da contra-seqüencialidade filtra somente dados contraseqüenciais: situações cujo ponto de referência aparece antes, em termos de codificação no discurso. À primeira vista, tanto o mais-que-perfeito contraseqüencial quanto o seqüencial poderiam ser incluídos como dados potenciais. Mas incluindo o mais-que-perfeito seqüencial, deveríamos incluir também o perfeito seqüencial, o que deixaria a análise inconsistente: primeiro, pelo grande número de dados de perfeito seqüencial versus um número muito pequeno de mais-queperfeito seqüencial; segundo, porque seria difícil detectar se o ponto de referência é uma situação passada ou o tempo de fala. 
O último obstáculo às variantes (pretérito perfeito e pretérito mais-queperfeito) é a possibilidade de serem substituídas. Nesta etapa, são excluídos, por exemplo, casos em que as orações em jogo (a que contém o ponto de referência e a que contém o possível dado de análise) estão ligadas pelo conectivo quando (cf. exemplo 8) porque a presença do mais-que-perfeito, na segunda oração, indica anterioridade e a presença do perfeito, cotemporalidade.

(8) Quando nós chegamos, às dez horas no ônibus, nosso ônibus tinha sido (foi) assaltado. (FLP09, L762)

\section{Análise quantitativa}

Nesta pesquisa, foram utilizadas trinta e seis entrevistas, realizadas em Florianópolis, cada uma com cerca de uma hora de duração. As gravações fazem parte do corpus do Projeto VARSUL. Encontramos, nas trinta e seis entrevistas, quinhentos e setenta e seis (576) dados que puderam ser filtrados pelas restrições impostas. Esses dados foram submetidos ao programa estatístico VARBRUL (PINTZUK, 1988).

A variável dependente foi constituída por duas formas de pretérito: pretérito mais-que-perfeito composto e pretérito perfeito anterior ${ }^{4}$. $\mathrm{O}$ pretérito mais-que-perfeito composto foi considerado a aplicação da regra. O pretérito maisque-perfeito simples não foi utilizado porque houve apenas duas ocorrências, ambas com valor de projeção futura.

\section{AS MOTIVAÇÕES}

Um estudo que se proponha de orientação funcionalista - como é o caso desta pesquisa - não pode se furtar de situar seu objeto de investigação em um domínio complexo, resultante da interação de motivações de natureza diversa. Dessa forma, nos propomos a controlar variáveis lingüísticas em diferentes níveis que vão desde um nível que podemos denominar de semântico-cognitivo, já que baseado na percepção de acontecimentos do mundo real, passando por um nível que podemos denominar de semântico-estrutural, mais facilmente captado na codificação lingüística, seja por relações de significação estabelecidas via conectores sintáticos, seja por traços de significação inerentes aos itens lexicais ou a morfemas gramaticais, até chegar a um nível que diríamos estrutural, essencialmente associado à codificação morfossintática, centrado na forma propriamente dita.

\footnotetext{
${ }^{4}$ Doravante, vamos nos referir às variantes como pretérito mais-que-perfeito e pretérito perfeito, tendo em vista, porém, que se trata, no primeiro caso, da forma composta e no segundo caso, da forma anterior. 
Por outro lado, como este é um estudo que se propõe também variacionista, é imprescindível que se controlem variáveis de natureza social ou extralingüística.

\section{Variáveis lingüísticas}

Das variáveis lingüísticas categorizadas, serão apresentadas apenas aquelas mais relevantes do ponto de vista estatístico: paralelismo formal, tipo de verbo da situação variável, advérbio da situação variável, tipo de ponto de referência e tipo de verbo do ponto de referência.

\section{Paralelismo Formal ${ }^{5}$ (primeiro grupo selecionado)}

Consideramos como paralelas ao pretérito mais-que-perfeito tanto as formas de pretérito imperfeito quanto as de pretérito mais-que-perfeito por trazerem uma forma de imperfeito no auxiliar, e como paralelas ao pretérito perfeito apenas formas de pretérito perfeito. Considerem-se os seguintes exemplos:

(9) Tinha uma moça antes de mim, que TINHA ESTOURADO a bolsa, e eles simplesmente botaram um papel e me colocaram em cima. (FLP 20, L859)

(10) Consegui na espera, em sexto lugar, porque DESISTIRAM dezessete crianças... (FLP 09, L619)

Nossa hipótese se refere ao aparecimento do pretérito mais-que-perfeito quando o verbo da oração imediatamente anterior aparecer com uma forma de imperfeito.

Outras formas verbais anteriores ao dado em análise foram categorizadas sob os rótulos 'forma não flexionada' e 'outros'. Mas, neste caso, o paralelismo não está atuando. Já que variam apenas os pretéritos perfeito e mais-que-perfeito, a escolha deve, então, ser fruto de outros fatores. Seguem-se os resultados:

Uso do pretérito mais-que-perfeito em relação ao paralelismo formal, em Florianópolis, na amostra do VARSUL

\begin{tabular}{|c|c|c|c|}
\hline Fator & Aplicação/ Total & Percentagem & Peso relativo \\
\hline Formas de Imperfeito $^{6}$ & $65 / 150$ & $43 \%$ & 0,67 \\
\hline Outros & $15 / 57$ & $26 \%$ & 0,67 \\
\hline Forma não flex. & $09 / 33$ & $27 \%$ & 0,53 \\
\hline Pretérito Perfeito & $52 / 336$ & $15 \%$ & 0,39 \\
\hline Total & $141 / 576$ & $24 \%$ & \\
\hline
\end{tabular}

Fig.1

\footnotetext{
${ }^{5}$ Algumas formas verbais não foram consideradas no paralelismo formal porque são expressões ou de natureza modal ou discursiva (não sei, parece, quer dizer, segundo dizem).

${ }^{6}$ Uma rodada prévia com as formas de imperfeito separadas (imperfeito do verbo ter, outras formas de imperfeito e pretérito mais-que-perfeito) demonstrou que os dois primeiros fatores favorecem o pretérito mais-que-perfeito e que o mais-que-perfeito apresenta um comportamento neutro, por isso resolvemos amalgamá-las.
} 
A utilização do pretérito mais-que-perfeito paralela a formas de imperfeito se justifica pelo paralelismo ("marcas levam a marcas e zeros levam a zeros" POPLACK, 1979, p.80). A baixa ocorrência, por outro lado, do pretérito perfeito igualmente evidencia tendência ao paralelismo (pretérito perfeito leva ao pretérito perfeito).

Tipo de verbo da situação (terceiro grupo selecionado)

Para a classificação dos verbos, tanto da situação variavelmente codificada como da situação correspondente ao ponto de referência, foi utilizada a tipologia verbal quadripartida proposta por Vendler (1967), assentada em valores aspectuais e constituída pelos seguintes tipos de verbos: activities, accomplishments, achievements e states. Essa classificação, conforme Godoi (1992, p.21), "é ontológica, representa as categorias situacionais que são partes do mundo como nós o percebemos e conhecemos (...) A quadripartição é feita no nível lexical (...) Mas Vendler parece estar ciente de que suas categorias dizem respeito a expressões sintaticamente complexas sendo exemplar o caso do objeto direto que determina a qual das categorias o verbo pertence."

Para Vendler (op. cit.), atividades não precisam de um término, sendo verdadeiras mesmo quando interrompidas; Godoi (op. cit.), interpretando Vendler, coloca que atividades são situações de duração temporal indefinida, não envolvendo culminação. Os accomplishments referem-se a um segmento inteiro de tempo; uma situação do tipo accomplishment deve necessariamente evidenciar o ponto final. Os achievements se referem a situações pontuais; de acordo com Vendler, esses verbos captam o começo ou o clímax de uma situação e não podem acontecer em uma extensão temporal. E situações estáticas ocorrem em todos os instantes de um período de tempo. Além das quatro categorias verbais apontadas por Vendler (op.cit.), consideramos, ainda, os verbos dicendi que, em sua maioria, aparecem como retomadas discursivas, quando representam a situação em análise. A seguir, apresentamos exemplos desses tipos verbais:

(11) Aí os vizinhos iam fazer queixa que eu TINHA JOGADO bola. (FLP 18, L1039)

(12) Então a gente brincava de casinha, tinha a casinha de um curral de porco, né? Que o pai TINHA FEITO um curral, tinha bastante bichos... (FLP 09, L05)

(13) Aí eu peguei, telefonei pra Macarronada e descobri que [ele tinha]- ACONTECEU um acidente. (FLP 03, L867)

(14) Porque quando eu fiquei doente, eu já estava grande, né? Mas em pequena, pequena mesmo, caxumba, essas coisas, eu não TIVE... (FLP 01, L996)

(15) ...nós morávamos numa chácara, como eu FALEI, a chácara era do seu Italino... (FLP 08, L802)

Os resultados iniciais mostraram que a divisão quadripartida baseada principalmente na duração e delimitação não foi relevante; o que se mostrou pertinente foi a oposição quanto ao traço de dinamicidade. Os percentuais 64 
associados a cada tipo de verbo foram: achievement, 31\%; accomplishment, $29 \%$; atividade, $35 \%$; e estado, $13 \%$. A partir destes resultados, foram amalgamados os tipos atividade, accomplishment e achievement, que representam situações dinâmicas; os estados, que representam situações menos dinâmicas, e verbos dicendi permaneceram como anteriormente apresentados. Considerem-se os resultados:

Uso do pretérito mais-que-perfeito em relação ao tipo de verbo da situação do passado anterior, em Florianópolis, na amostra do VARSUL

\begin{tabular}{|c|c|c|c|}
\hline Fator & Aplicação/Total & Percentagem & Peso relativo \\
\hline Situações + dinâmicas & $107 / 348$ & $31 \%$ & 0,63 \\
\hline Situações dicendi & $08 / 78$ & $10 \%$ & 0,35 \\
\hline Situações - dinâmicas & $26 / 150$ & $17 \%$ & 0,29 \\
\hline Total & $141 / 576$ & $24 \%$ & \\
\hline
\end{tabular}

Fig.2

Situações dinâmicas $(0,63)$ condicionam o aparecimento do pretérito mais-que-perfeito. Possivelmente requerem uma forma de codificação marcada, já que são mais salientes por conduzirem a seqüência de ações, normalmente em figura $^{7}$, no fluxo discursivo. Neste caso, a marcação pode ser explicada também pela complexidade estrutural e pela distribuição de freqüência, que são dois dos critérios apresentados por Givón (1991b, p.106) para analisar a marcação.

Por outro lado, situações menos dinâmicas desfavorecem o pretérito maisque-perfeito. Isso, em princípio, se justifica porque os estados não são salientes do ponto de vista perceptual e normalmente correspondem a informação de fundo na cadeia discursiva. Além disso, estados ocupam uma extensão de tempo maior, sendo, então, mais compatíveis com a utilização do pretérito perfeito, que pode evidenciar uma aproximação com o ponto de referência.

Estamos utilizando os critérios de saliência perceptual, complexidade estrutural e distribuição de freqüência para considerar o pretérito mais-que-perfeito como a categoria marcada. Note-se, entretanto, que todos os nossos dados em análise (incluindo a variante no pretérito perfeito) são contra-seqüenciais, por isso, marcados por natureza (GIVÓN, 1995). O pretérito mais-que-perfeito representa, pois, a forma verbal mais marcada, e não a estrutura sintática mais marcada, em termos de codificação contra-seqüencial (já que no caso das duas variantes a ordem é marcada).

Advérbio da situação (quarto grupo selecionado)

Os advérbios, conforme Godoi (1992, p.215), “não só modificam os predicados mas podem desempenhar um papel ativo na determinação da

${ }^{7}$ Koffka (1936/1975) descreve o plano ambiental como duplamente organizado (figura/fundo). A figura constitui o relevo, por isso é percebida como mais saliente, e o fundo aparece como suporte, caracterizando-se como neutro. In: Princípios da psicologia da Gestalt. São Paulo, Cultrix. 
interpretação da sentença." Neste grupo, foram considerados: advérbios de tempo (por exemplo, antes, ontem, semana passada), especificamente o advérbio já, oração temporal e os advérbios de negação não e nunca. Considerem-se os seguintes exemplos:

(16) Não, é que eu troquei de carro, então TINHA TIRADO antes. (FLP10, L1233)

(17) Porque aí eu não queria mais viver com ele, que aí eu estava revoltada com ele, que eu já TINHA VISTO aquilo tudo, né?... (FLP 03, L977)

(18) Uma vez eu vim de ônibus, o carro QUEBROU quando eu estava andando. (FLP 10, L899)

(19) Aí eu pedi desculpa pra ele várias vezes que a intenção minha não FOI ofender. (FLP 14, L125)

(20) E. Ah! Qual o filme que o senhor assistiu ontem? F. Eu sei que um filme de bandido mesmo, que eu nunca $\mathrm{VI}^{8}$ matar tanto. (FLP 05, L236)

Considerem-se os resultados:

Uso do pretérito mais-que-perfeito em relação ao advérbio da situação variável, em Florianópolis, na amostra do VARSUL

\begin{tabular}{|c|c|c|c|}
\hline Fator & Aplicação/ Total & Percentagem & Peso Relativo \\
\hline Já & $30 / 56$ & $54 \%$ & 0,88 \\
\hline Nunca & $10 / 25$ & $40 \%$ & 0,77 \\
\hline Não & $06 / 37$ & $16 \%$ & 0,56 \\
\hline Advérbio de tempo & $11 / 72$ & $15 \%$ & 0,18 \\
\hline Oração temporal & $02 / 19$ & $11 \%$ & 0,11 \\
\hline Total & $59 / 209$ & $28 \%$ & \\
\hline \multicolumn{2}{|c|}{ Fig.3 }
\end{tabular}

O advérbio já favorece o pretérito mais-que-perfeito. Parece que, em português, há uma forte tendência no sentido de associar o advérbio $j a ́$ ao pretérito mais-que-perfeito. Esse parece ser também o caso do inglês. Normalmente, o past perfect associa-se ao advérbio already. Talvez seja possível falar em especialização de uso em direção a um processo de gramaticalização decorrente da recorrência de certas construções.

O peso associado ao advérbio nunca é maior que o peso do advérbio não, embora ambos indiquem que o verbo que os acompanha é de estado'. Isso se explica porque o advérbio nunca, diferentemente de não, pode negar todo o

\footnotetext{
${ }^{8}$ Nesse caso, nunca vi é considerado como um tempo passado anterior porque é anterior a assistir, que é passado em relação ao tempo de fala.

${ }^{9}$ Consideramos todas as situações negadas como estáticas. Para maiores esclarecimentos, consultar Coan, 1997, p.110 (Dissertação de Mestrado).

66
} 
período passado, não apenas um período no passado. Associar o advérbio nunca ao pretérito mais-que-perfeito implica marcar a terminação de uma situação antes de outro tempo passado sem qualquer ambigüidade (...nunca tinha visto/nunca vi). $\mathrm{O}$ fato de o advérbio não favorecer ou pelo menos mostrar que tende ao uso do pretérito mais-que-perfeito poderia ser justificado pelo interesse do informante de marcar a situação negada, enfatizando, assim, o não acontecimento.

O peso atribuído aos advérbios temporais indica que tais expressões favorecem o pretérito perfeito, o que se justifica pela não necessidade de marcar uma situação já marcada temporalmente. Esse comentário pode ser aplicado também para os casos de oração temporal.

Tipo de ponto de referência (quinto grupo selecionado)

A categorização deste grupo foi pautada em uma tipologia de pontos de referência que inclui ponto de referência verbal, contextual e adverbial, com possíveis desdobramentos ${ }^{10}$. Por ser de grande valia na determinação do dado variável, nesta pesquisa, acreditamos que o ponto de referência tenha um papel importante na escolha entre os pretéritos perfeito e mais-que-perfeito. Consideramos os seguintes tipos de ponto de referência, quanto à sua codificação: presença de forma não-flexionada (resultado da amalgamação de forma não flexionada - 0,84 e locução verbal - 0,75), forma verbal flexionada, inferência pela negação e ponto de referência discursivo. Vejam-se os exemplos abaixo:

(21) Qual a minha surpresa, que nesse ínterim, tá? começou a aparecer várias dívidas que o Osni TINHA CONTTRAÍDO. (FLP 23, L205)

(22) Aí contou, né? que TINHA se QUEIMADO e tudo. (FLP 03, L916)

(23) $F$. Eu nasci em setenta e quatro então- $E$. Não existias ainda? $F$. Não, nunca TINHA PRESENCIADO. (FLP Leda/11)

(24) (...) É como eu já TINHA FALADO anteriormente: quem tinha lá cento e cinqüenta mil cruzeiros, quer dizer, foi confiscado. (FLP 02, L358)

$\mathrm{Na}$ análise dos dados, obtivemos os seguintes resultados:

${ }^{10}$ Para maiores detalhes, verificar a tipologia de pontos de referência em Coan, 1997, p.68 (Dissertação de Mestrado). 
Uso do pretérito mais-que-perfeito em relação ao tipo de ponto de referência, em Florianópolis, na amostra do VARSUL

\begin{tabular}{|c|c|c|c|}
\hline Fator & Aplicação/ Total & Percentagem & Peso relativo \\
\hline Inferência pela negação & $05 / 10$ & $50 \%$ & 0,83 \\
\hline Presença de forma não-flex. & $44 / 107$ & $41 \%$ & 0,75 \\
\hline Forma flexionada & $87 / 395$ & $22 \%$ & 0,58 \\
\hline Discursivo & $05 / 64$ & $08 \%$ & 0,02 \\
\hline Total & $141 / 576$ & $24 \%$ & \\
\hline
\end{tabular}

Fig.4

O pretérito mais-que-perfeito é altamente favorecido pelos tipos 'inferência pela negação' $(0,83)$ e 'presença de forma não flexionada' $(0,75)$. No primeiro caso, a tendência ao uso do pretérito mais-que-perfeito se deve, possivelmente, ao não aparecimento de uma forma verbal como ponto de referência no discurso. Assim, é mais fácil processar a informação na presença do pretérito mais-que-perfeito do que na presença do pretérito perfeito, que muitas vezes indica duração até o tempo de fala. $\mathrm{O}$ alto peso associado a 'presença de forma não-flexionada' deve ter ocorrido porque há no ponto de referência um tempo relativo. Em princípio, o processo de interpretação gira em torno da especificação do tempo relativo, o que o torna mais lento. Esse processamento deve ser facilitado quando a forma seguinte é um pretérito mais-que-perfeito.

Tipo de verbo do ponto de referência ( sexto grupo selecionado)

A categorização deste grupo também foi pautada na tipologia verbal proposta por Vendler (1967). Nossa hipótese, agora, baseia-se no traço duratividade, por acreditarmos que situações mais estendidas (no ponto de referência) devam requerer mais marcação (na situação de passado anterior) com vistas a indicar mais claramente a anterioridade de uma situação em relação à outra. Vejam-se os resultados:

Uso do pretérito mais-que-perfeito em relação ao tipo de verbo do ponto de referência, em Florianópolis, na amostra do VARSUL

\begin{tabular}{|l|l|l|l|}
\hline Fator & Aplicação/ Total & Percentagem & Peso relativo \\
\hline Atividade & $05 / 08$ & $63 \%$ & 0,97 \\
\hline Estado & $45 / 162$ & $28 \%$ & 0,55 \\
\hline Dicendi & $28 / 82$ & $34 \%$ & 0,54 \\
\hline Accompl./achievement & $50 / 246$ & $20 \%$ & 0,02 \\
\hline Total & $128 / 498$ & $26 \%$ & \\
\hline
\end{tabular}

O pretérito mais-que-perfeito é favorecido quando há verbo de atividade e de estado no ponto de referência. Acreditamos que o fato de estados e atividades possuírem um componente durativo deve favorecer o aparecimento do pretérito mais-que-perfeito para que as dimensões temporais passadas, envolvendo dado 68 
variável e ponto de referência, estejam especificadas. A utilização, por outro lado, do pretérito perfeito poderia, à primeira vista, gerar interpretação de cotemporalidade.

Note-se que o critério da extensão temporal parece dominar e determinar as escolhas. Se o ponto de referência é mais estendido, então predomina o pretérito mais-que-perfeito. Por outro lado, quando o ponto de referência é menos estendido no tempo, ocorre o pretérito perfeito ${ }^{11}$. A ocorrência de 0,42 para accomplishment/achievement indica que verbos deste tipo inclinam-se a favorecer o pretérito perfeito por denotarem situações bem delimitadas temporalmente, não necessitando, portanto, de marcação.

Verbo dicendi também apresenta um peso relativo favorável ao pretérito mais-que-perfeito, talvez porque estruturas envolvendo discurso indireto sejam aquelas ensinadas formalmente como características de uso de tal forma de pretérito.

\section{Variáveis sociais}

Arrolamos, neste trabalho, as variáveis externas estratificadas, idade, sexo e escolaridade, as quais foram controladas na organização do banco de dados do Projeto VARSUL e igualmente consideradas na constituição do corpus deste trabalho, com o objetivo de testar sua influência na escolha das variantes em estudo. Acreditamos, de acordo com Du Bois (1987), que as motivações sociais se confrontam e interagem com as motivações internas com profundas conseqüências. E que o contínuo da evolução lingüística depende da oscilação entre processos internos de generalização estrutural e sua interação com o sistema social externo. (LABOV, 1970 apud DU BOIS op.cit. $)^{12}$.

Focalizamos, a seguir, a variável idade, única selecionada dentre as sociais. As variáveis sexo e escolaridade aparecem apenas correlacionadas à idade.

\section{Idade (segundo grupo selecionado)}

Os dados em análise estão distribuídos por três faixas etárias, respectivamente, informantes com idade entre quinze e vinte e quatro anos, vinte $\mathrm{e}$ cinco e quarenta e nove anos e mais de cinqüenta anos. Nossa hipótese, neste caso, se refere a uma possível mudança, captada em tempo aparente, no sentido de que os mais jovens devem tender à inovação (entendida como uso mais freqüente do pretérito perfeito) e os mais velhos à preservação da forma mais antiga (predominância do pretérito mais-que-perfeito), enquanto que os indivíduos de meia idade devem demonstrar um comportamento neutro.

\footnotetext{
${ }^{11}$ Zilles, em comunicação pessoal, chama atenção para que se verifique e discuta o caráter télico da situação, a culminância, e não apenas a duração. Oportunamente, trataremos do assunto.

${ }^{12}$ LABOV, W. The study of language in its social context. Studium Generale 23, 1970.
} 
Uso do pretérito mais-que-perfeito em relação à idade, em Florianópolis, na amostra do VARSUL

\begin{tabular}{|c|c|c|c|}
\hline Fator & Aplicação/ Total & Percentagem & Peso relativo \\
\hline + de 50 anos & $34 / 156$ & $22 \%$ & 0,59 \\
\hline $25-49$ anos & $78 / 204$ & $38 \%$ & 0,70 \\
\hline 15-25 anos & $29 / 216$ & $13 \%$ & 0,26 \\
\hline Total & $141 / 576$ & $24 \%$ & \\
\hline \multicolumn{4}{|c|}{ Fig.6 }
\end{tabular}

Os falantes mais jovens tendem à utilização da forma de pretérito perfeito, enquanto os mais velhos inclinam-se ao emprego do pretérito mais-que-perfeito. Destaque-se, porém, que os que mais usam a forma considerada "mais antiga" são os de meia idade. Acreditamos ser possível, em função dos resultados, aventar a possibilidade de estar ocorrendo uma mudança em tempo aparente.

Idade e sexo

Devido ao fato de a variável idade ter sido selecionada, cruzamos idade e sexo para verificar a atuação da variável idade por sexo, com a expectativa de que a utilização do pretérito mais-que-perfeito fosse mais recorrente nos dados de mulheres mais velhas, enquanto que, entre os jovens, a maior aproximação de homens e mulheres se refletisse também no uso da língua.

Uso do pretérito mais-que-perfeito em relação à atuação da idade por sexo, em Florianópolis, na amostra do VARSUL

\begin{tabular}{|c|c|c|c|c|c|c|}
\hline & \multicolumn{3}{|c|}{ Masculino } & \multicolumn{3}{c|}{ Feminino } \\
\hline & Apl./Total & $\%$ & PR & Apl./Total & $\%$ & PR \\
\hline 15-24 anos & $14 / 112$ & 13 & 0,26 & $15 / 104$ & 14 & 0,24 \\
\hline 25-50 anos & $15 / 49$ & 31 & 0,76 & $63 / 155$ & 41 & 0,70 \\
\hline + de 50 anos & $23 / 106$ & 22 & 0,60 & $11 / 50$ & 22 & 0,54 \\
\hline Total & $66 / 267$ & 25 & & $89 / 309$ & 29 & \\
\hline
\end{tabular}

Os resultados demonstram um comportamento semelhante entre homens e mulheres nas três faixas etárias. Isso, em princípio, significa que as mulheres, no fenômeno de variação entre os pretéritos mais-que-perfeito e perfeito, não são mais sensíveis " à norma". É possível que esse comportamento mais "frouxo" (contrariamente ao esperado) por parte das mulheres se deva ao traço de variante não estigmatizada que caracteriza o pretérito perfeito.

Idade e Escolaridade

A variável escolaridade também foi cruzada com idade. Vejamos os resultados: 
Uso do pretérito mais-que-perfeito em relação à atuação da idade por escolaridade, em Florianópolis, na amostra do VARSUL

\begin{tabular}{|c|c|c|c|c|c|c|c|c|c|}
\hline & \multicolumn{4}{|c|}{ Primário } & \multicolumn{3}{c|}{ Ginasial } & \multicolumn{3}{c|}{ Colegial } \\
\hline & Apl./Total & $\%$ & PR & Apl./Total & $\%$ & PR & Apl./Total & $\%$ & PR \\
\hline 15-24 anos & $08 / 69$ & 12 & 0,19 & $08 / 86$ & 09 & 0,17 & $13 / 61$ & 21 & 0,48 \\
\hline 25-49 anos & $37 / 85$ & 44 & 0,76 & $14 / 40$ & 35 & 0,72 & $27 / 79$ & 34 & 0,66 \\
\hline + de 50 anos & $04 / 23$ & 17 & 0,61 & $13 / 59$ & 22 & 0,52 & $17 / 74$ & 23 & 0,62 \\
\hline Total & $49 / 177$ & 28 & & $35 / 185$ & 19 & & $57 / 214$ & 27 & \\
\hline
\end{tabular}

Informantes com nível de escolaridade primário e ginasial apresentam um comportamento muito semelhante entre si, mantendo as distâncias já evidenciadas entre as faixas de idade: uma alteração de comportamento abrupta entre os mais jovens e a faixa intermediária dos adultos (uma diferença em torno de 0,55 ), com uma sensível redução da diferença entre os adultos e os mais velhos (em torno de $0,20)$. Já os informantes de nível colegial apresentam um comportamento mais aproximado entre as diferentes faixas etárias (com uma diferença de 0,18 entre jovens e adultos e 0,04 entre estes e os mais velhos).

Por outro lado, é na faixa dos mais jovens que se observa que a escola parece exercer algum efeito, pois os pesos relativos sobem de 0,19/0,17 (primário/ginásio) para 0,48 (colegial). Este resultado é perfeitamente justificado, visto que os jovens de nível colegial entrevistados estavam concluindo o segundo grau, ou já haviam concluído e encontravam-se em fase de preparação para o vestibular. Em contrapartida, os jovens com escolaridade até a oitava série, ou abandonaram a escola há algum tempo ou apresentavam algum índice de repetência.

\section{CONSIDERAÇÕES FINAIS}

Demonstramos, neste trabalho, que os pretéritos mais-que-perfeito e perfeito comportam-se como variantes quando codificam um tempo passado, perfectivo, anterior a um ponto de referência passado.

Apresentamos, também, alguns procedimentos metodológicos, enfatizando-se a necessidade de restringir a variável em estudo através de critérios, com o intuito de identificar as variantes como portadoras do mesmo significado representacional. Finalmente, a combinação de fatores semânticos, estruturais e sociais nos permitiu delinear o contexto prototípico de ocorrência dos pretéritos mais-que-perfeito e perfeito. A análise realizada evidenciou a existência de "motivações em competição", situando-se o fenômeno investigado num domínio funcional complexo, sofrendo atuação de forças de naturezas distintas (lingüísticas e sociais). A correlação função-forma foi bastante significativa se observarmos os contextos prototípicos ao aparecimento das variantes. 
A seguir, apresentamos um quadro comparativo entre os pretéritos maisque-perfeito e perfeito a partir dos resultados obtidos na análise lingüística e social. Os grupos de fatores estão arranjados por ordem de seleção estatística.

Quadro comparativo entre os pretéritos mais-que-perfeito e perfeito a partir dos resultados obtidos na análise de
grupos de fatores lingüísticos e sociais

\begin{tabular}{|c|c|c|}
\hline Grupos de fatores & Pretérito mais-que-perfeito & Pretérito perfeito \\
\hline Paralelismo formal & Formas de imperfeito & Pretérito perfeito \\
\hline Idade & $25-49$ anos & $15-24$ anos \\
& + de 50 anos & \\
\hline Tipo de verbo da Situação & Situação mais dinâmica & $\begin{array}{c}\text { Situação menos dinâmica } \\
\text { Verbo dicendi }\end{array}$ \\
\hline Advérbio da Situação & Já & Oração temporal \\
& Nunca & Advérbio de tempo \\
& Não & Discursivo \\
\hline Tipo de Ponto de & Inferência pela negação & \\
Referência & Forma não-flex./flex. & Accompl./achievement \\
\hline Tipo de verbo do Ponto de & Atividade & \\
Referência & Estado & \\
& DICENDI & \\
\hline
\end{tabular}

Fig.9

O quadro acima demonstra os contextos preferenciais para o uso das variantes sob análise. Não utilizamos o pretérito perfeito pelo pretérito mais-queperfeito, simplesmente, porque essas formas estão disponíveis no sistema; pressões semânticas, estruturais e sociais estão, freqüentemente, determinando nossas escolhas.

\section{BIBLIOGRAFIA}

AlmeIDA, N. M. Gramática Metódica da Língua Portuguesa. São Paulo, Saraiva, 1982.

CAMARA Jr., J. M. História e Estrutura da Lingua Portuguesa. Rio de Janeiro, Padrão, 1985.

COAN, M. Anterioridade a um ponto de referência passado: pretérito (mais-que) perfeito. UFSC,Florianópolis, 1997 . Dissertação de Mestrado.

COMRIE, B. Aspect. 3. ed.. Cambridge, Cambridge University Press, 1981.

Tense. 4 ed. Cambridge, Cambridge University Press, 1990.

CUNHA, C. e CINTRA, L. Nova Gramática do Português Contemporâneo. Rio de Janeiro, Nova Fronteira, 1985.

DUBOIS, J. The discourse basis of ergativity. Language, Baltimore, v. 63, n. 4, p. 805-55, 1987.

GIVÓN, T. Syntax: a functional - typological introduction, v. II. Amsterdam,Philadelphia, Benjamins, 1990. 
. Functionalism and grammar: a prospectus. University of Oregon, 1991a.

- Isomorphism in the grammatical code: cognitive and biological considerations. In: Studies in language. Amsterdam,Philadelphia, J. Benjamins, $1991 b$.

. Verbal inflections: tense, aspect, modality and negation. In: English grammar: a functional-based introduction. v. I e II. Amsterdam, Philadelphia, J. Benjamins, 1993.

. Functionalism and grammar. Amsterdam,Philadelphia, J. Benjamins, 1995.

GODOI, E. Aspectos do aspecto. Campinas, 1992. Tese de Doutorado.

LABOV, W. Where does the linguistic variable stop? A response to Beatriz Lavandera. Sociolinguistic Working Papers, Texas, v. 44, p.1-17, 1978.

LAVANDERA, B. Where does the sociolinguistic variable stop? A response to Beatriz Lavandera. Language in Society, Great Britain, v. 7, n.2, p. 171-82, 1978.

PAREDES DA SILVA, V. L. A abordagem laboviana. Anais do VII Encontro da ANPOLL. Goiânia, 1993.

PINTZUK, S. VARBRUL Programs. 1988. mimeo.

POPLACK, S. Function and process in a variable phonology. (University of Pennsylvania Dissertation), 1979.

ROCHA LiMA, C. H. Gramática normativa da Língua Portuguesa. Rio de Janeiro, José Olympio , 1976.

SAID ALI, M. Gramática secundária e gramática histórica da Língua Portuguesa. Brasília, Ed. Universidade de Brasília, 1964.

VENDLER, Z. verbs and times. linguistics and philosophy. Ithaca, New York, Cornell University Press, 1967. 